$05,11,12$

\title{
Эффект памяти формы в микроразмерном образце сплава Гейслера $\mathrm{Ni}-\mathrm{Mn}-\mathrm{Ga}-\mathrm{Cu}$
}

\author{
(C) А.В. Маширов ${ }^{1,2}$, А.В. Иржак ${ }^{3}$, А.В. Кошелев ${ }^{4}$, Н.В. Андреев ${ }^{3}$, К.А. Колесов ${ }^{5}$, \\ А.П. Каманцев ${ }^{1}$, В.В. Коледов ${ }^{1}$, В.Г. Шавров ${ }^{1}$ \\ ${ }^{1}$ Институт радиотехники и электроники им. В.А. Котельникова РАН, \\ Москва, Россия \\ ${ }^{2}$ Балтийский федеральный университет им. Иммануила Канта, \\ Калининград, Россия \\ ${ }^{3}$ Национальный исследовательский технологический университет „МИСИС“, \\ Москва, Россия \\ ${ }^{4}$ Московский государственный университет им. М.В. Ломоносова, \\ Москва, Россия \\ ${ }^{5}$ Московский государственный технический университет им. Н.Э. Баумана, \\ Москва, Россия \\ E-mail: a.v.mashirov@mail.ru
}

Поступила в Редакцию 30 декабря 2019 г.

В окончательной редакции 30 декабря 2019 г.

Принята к публикации 10 января 2020 г.

Продемонстрирован эффект памяти формы в ферромагнитном микрообразце сплава Гейслера $\mathrm{Ni}_{50} \mathrm{Mn}_{18.5} \mathrm{Ga}_{25} \mathrm{Cu}_{6.5}$. Микрообразец был изготовлен при помощи технологии фокусированного ионного пучка и имеет габаритные размеры $23 \times 1.28 \times 4 \mu \mathrm{m}$. Было обнаружено, что значение упругой деформации в мартенситной фазе превышает значение эффекта памяти формы, в основе которого лежит остаточная деформация за счет двойникования. Максимальное значение эффекта памяти формы составило 3.4\%.

Ключевые слова: эффект памяти формы на микромасштабе, $\mathrm{Ni}-\mathrm{Mn}-\mathrm{Ga}-\mathrm{Cu}$, сплавы Гейслера.

DOI: $10.21883 /$ FTT.2020.06.49338.35M

\section{1. Введение}

В сплавах Гейслера семейства $\mathrm{Ni}-\mathrm{Mn}-\mathrm{Ga}$ наблюдается магнитоструктурный фазовый переход [1]. Магнитосруктурному фазовому переходу в ферромагнитных сплавах Гейслера $\mathrm{Ni}-\mathrm{Mn}-\mathrm{Ga}$ сопутствуют гигантский магнитокалорический эффект [2] и эффект памяти формы $[3,4]$, поэтому сплавы Гейслера семейства $\mathrm{Ni}-\mathrm{Mn}-\mathrm{Ga}$ рассматривают в качестве кандидатов для применения в магнитном охлаждении [5] и для создания исполнительных элементов магниточувствительных микроэлектромеханических систем [6-9]. В работе [6] было экспериментально показано, что для проявления эффекта магнитной памяти формы в микроразмерном образце из сплава $\mathrm{Ni}-\mathrm{Mn}-\mathrm{Ga}$ необходимо магнитное поле около 6-8Т. В свою очередь авторами [10] был синтезирован сплав $\mathrm{Ni}-\mathrm{Mn}-\mathrm{Ga}-\mathrm{Cu}$, в котором для реализации полного магнитоструктурного фазового перехода и, как следствие эффекта магнитной памяти формы было достаточно магнитного поля 3-4 Т. В связи с этим исследование эффекта памяти формы в сплаве $\mathrm{Ni}-\mathrm{Mn}-\mathrm{Ga}-\mathrm{Cu}$ представляет повышенный интерес. В данной работе была поставлена цель продемонстрировать эффект памяти формы при термоциклировании в ферромагнитном сплаве Гейслера $\mathrm{Ni}_{50} \mathrm{Mn}_{18.5} \mathrm{Ga}_{25} \mathrm{Cu}_{6.5}$.

\section{2. Синтез образца сплава Гейслера $\mathrm{Ni}_{50} \mathrm{Mn}_{18.5} \mathrm{Ga}_{25} \mathrm{Cu}_{6.5}$}

В данной работе исследовался микрообразец, изготовленный из сплава Гейслера номинальной композиции $\mathrm{Ni}_{50} \mathrm{Mn}_{18.5} \mathrm{Ga}_{25} \mathrm{Cu}_{6.5}$. Сплав Гейслера $\mathrm{Ni}_{50} \mathrm{Mn}_{18.5} \mathrm{Ga}_{25} \mathrm{Cu}_{6.5}$ был получен при помощи аргоннодуговой плавки коллегами D. Zhao и J. Liu из Института материаловедения и инженерии города Нимбо Китайской академии наук. Ими использовался метод направленного отвердевания и был выращен текстурированный поликристаллический стержень (со скоростью роста кристалла $150 \mu \mathrm{m} / \mathrm{s}$ ). Далее из стержня вырезалась заготовка образца размером $5 \times 5 \times 2 \mathrm{~mm}$, которая в дальнейшем подвергались гомогенизационному отжигу при 1073 К в течение 24 h в вакууме, а затем закалялась в ледяной воде. Рентгенограмма, полученная при комнатной температуре для заготовки образца номинальной композиции $\mathrm{Ni}_{50} \mathrm{Mn}_{18.5} \mathrm{Ga}_{25} \mathrm{Cu}_{6.5}$ показала, что в ней наблюдается моноклинная мартенситная структура [10]. Элементный химический состав заготовки образца определялся при помощи EDX-системы JED-2300, и его значение составило $\mathrm{Ni}_{50.14} \mathrm{Mn}_{18.36} \mathrm{Ga}_{25.28} \mathrm{Cu}_{6.22}$.

На рис. 1 приведена температурная зависимость намагниченности образца в магнитном поле 50 Ое. Данная зависимость была получена при помощи вибрационного магнитометра Quantum Design PPMS 9T, масса образца 


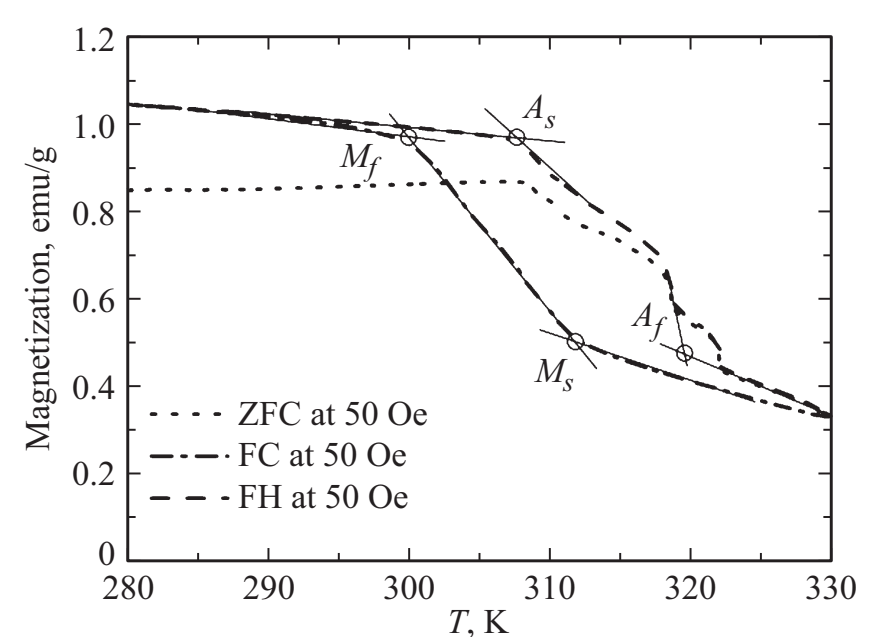

Рис. 1. Температурная зависимость намагниченности образца сплава Гейслера $\mathrm{Ni}_{50} \mathrm{Mn}_{18.5} \mathrm{Ga}_{25} \mathrm{Cu}_{6.5}$ в магнитном поле $50 \mathrm{Oe}$.

$1.24 \mathrm{mg}$. Из рисунка видно, что в температурном диапазоне $300-325 \mathrm{~K}$ образец из сплава $\mathrm{Ni}_{50} \mathrm{Mn}_{18.5} \mathrm{Ga}_{25} \mathrm{Cu}_{6.5}$ претерпевает магнитоструктурный фазовый переход с характерными температурами $M_{s}=311 \mathrm{~K}, M_{f}=300 \mathrm{~K}$, $A_{s}=307 \mathrm{~K}, A_{f}=319 \mathrm{~K}$, среднее значение ширины гистерезиса составило $7 \mathrm{~K}$. Мартенситный фазовый переход в данном сплаве совпадает с точкой Кюри и наблюдается фазовый переход 1-го рода из ферромагнитной мартенситной в парамагнитную аустенитную фазу (магнитоструктурный фазовый переход).

\section{3. Изготовление микрообразца $\mathrm{Ni}_{50} \mathrm{Mn}_{18.5} \mathrm{Ga}_{25} \mathrm{Cu}_{6.5}$ с эфффектом памяти формы}

C помощью технологии фокусированного ионного пучка в камере сканирующего ионного микро- скопа FIE Strata 201 был изготовлен микрокантилевер из ферромагнитного образца сплава Гейслера $\mathrm{Ni}_{50} \mathrm{Mn}_{18.5} \mathrm{Ga}_{25} \mathrm{Cu}_{6.5}$. Для чего из заготовки образца $\mathrm{Ni}_{50} \mathrm{Mn}_{18.5} \mathrm{Ga}_{25} \mathrm{Cu}_{6.5}$ методом ионного травления вырезалась ламель длиной 24 , толщиной 3 и шириной $4 \mu \mathrm{m}$, затем методом ионностимулированного осаждения платины из газовой фазы ламель припаивалась к игле наноманипулятора Omniprobe (рис. 2,a). Ламель утонялась до толщины $1.28 \mu \mathrm{m}$ (рис. $2, b)$. Свободный конец ламели припаивался к кремниевой пластине, а конец, припаянный к игле наноманипулятора Omniprobe, ионным травлением отрезался от иглы (рис. 2,c). В результате был изготовлен гантелеобразный микрокантилевер длиной 23 , толщиной 1.28 и шириной $4 \mu \mathrm{m}$.

\section{4. Результаты и обсуждение}

Для того чтобы наблюдать эффект памяти формы в микрообразце ферромагнитного сплава Гейслера $\mathrm{Ni}_{50} \mathrm{Mn}_{18.5} \mathrm{Ga}_{25} \mathrm{Cu}_{6.5}$ его первоначально изгибали в мартенситной фазе следующим образом. Микрокантилевер $\mathrm{Ni}_{50} \mathrm{Mn}_{18.5} \mathrm{Ga}_{25} \mathrm{Cu}_{6.5}$ находился в камере сканирующего ионного микроскопа при комнатной температуре в моноклинной мартенситной фазе. Затем игла наноманипулятора Omniprobe подводилась к микрокантилеверу, и концом иглы проводился его поперечно-продольный изгиб (рис. 3,a). Параметры моноклинной кристаллической решетки мартенситной фазы следующие $a_{M}=4.251 \AA$, $b_{M}=5.500 \AA, c_{M}=29.285 \AA, \beta_{M}=92.878^{\circ}[10]$. Изогнутый микрокантилевер представляет собой изогнутую балку, на внешней стороне которой под действующим растягивающим напряжением формируются мартенситные домены преимущественно с вдоль расположенными длинными ребрами $c_{M}=29.285 \AA$ моноклинной кристаллической решетки. Внутренняя сторона изогнутого микрокантилевера тогда состоит в основном из мартенситных доменов с преимущественно поперек $a$

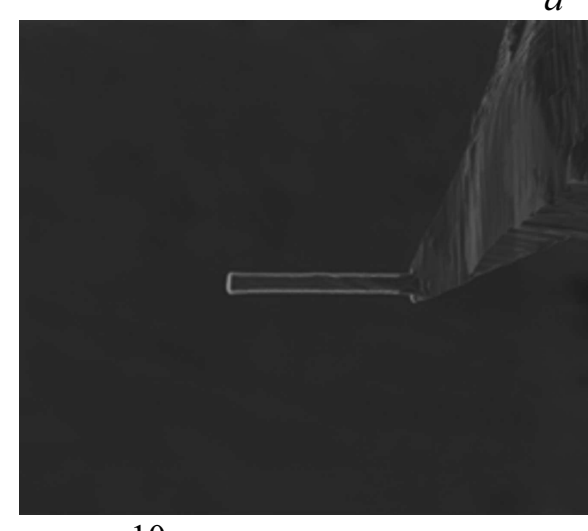

$-10 \mu \mathrm{m}$

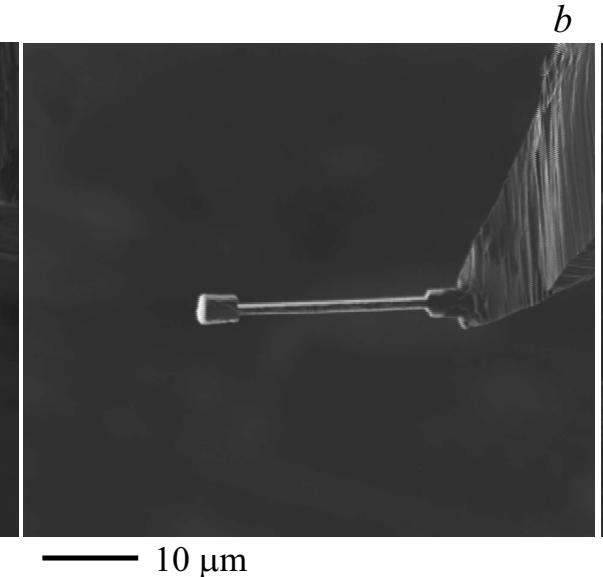

$b$

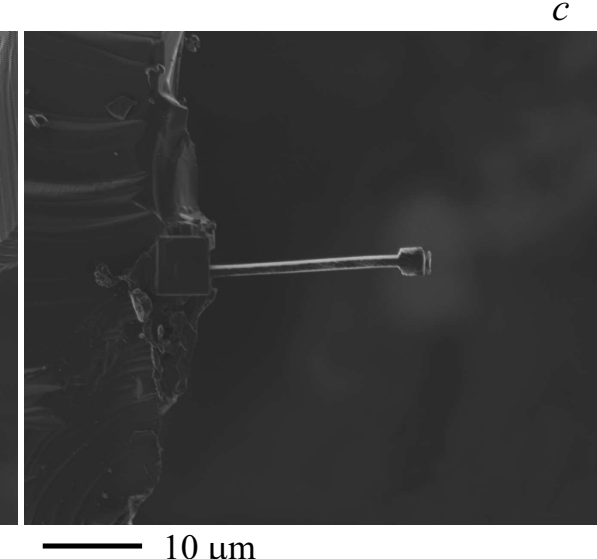

Рис. 2. (a) - изображение сканирующего ионного микроскопа FIE Strata 201, ламель $\mathrm{Ni}_{50} \mathrm{Mn}_{18.5} \mathrm{Ga}_{25} \mathrm{Cu}_{6.5}$ на игле наноманипулятора Omniprobe, $(b)$ - утонение до толщины $1.28 \mu$ m и придание гантелеобразной формы ламели $\mathrm{Ni}_{50} \mathrm{Mn}_{18.5} \mathrm{Ga}_{25} \mathrm{Cu}_{6.5},(c)-$ микрокантилевер $\mathrm{Ni}_{50} \mathrm{Mn}_{18.5} \mathrm{Ga}_{25} \mathrm{Cu}_{6.5}$ в заделке кремниевой пластины. 


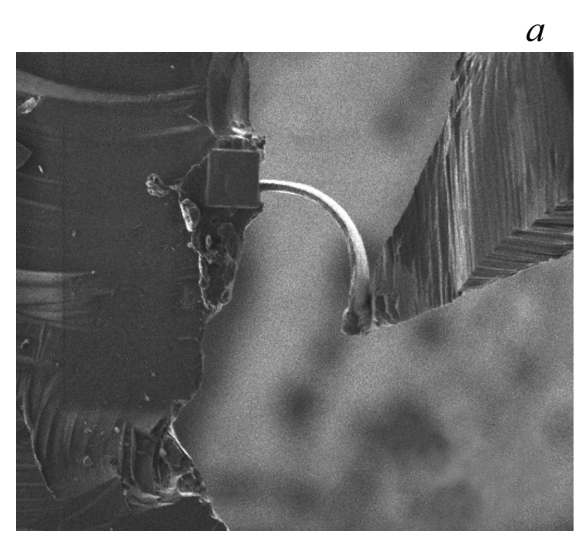

$-10 \mu \mathrm{m}$

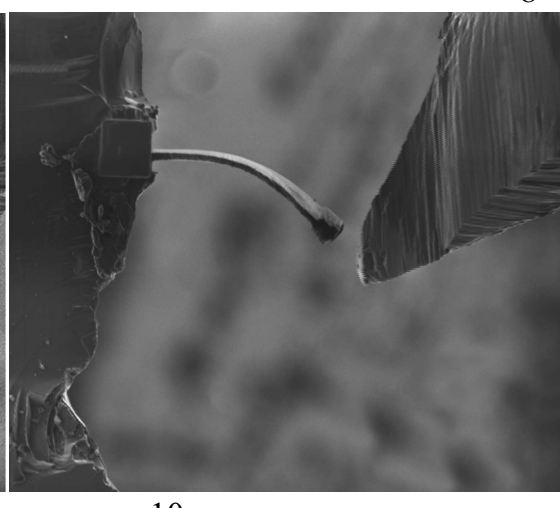

$b$

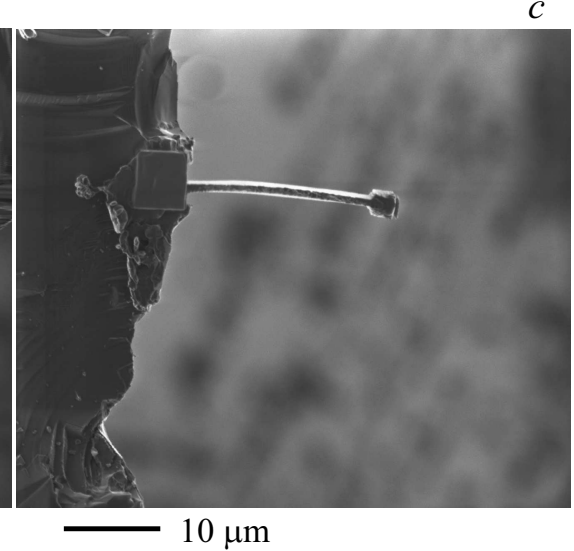

Pис. 3. (a) - изображение сканирующего ионного микроскопа FIE Strata 201, визуализирующее процесс механической деформации (сверхупругая деформации) микрокантилевера $\mathrm{Ni}_{50} \mathrm{Mn}_{18.5} \mathrm{Ga}_{25} \mathrm{Cu}_{6.5}$ иглой наноманипулятора Оmпірrobe в мартенсите, (b) - визуализация деформированного образца $\varepsilon=3.4 \%$ кантилевера $\mathrm{Ni}_{50} \mathrm{Mn}_{18.5} \mathrm{Ga}_{25} \mathrm{Cu}_{6.5}$ в мартенсите после деформации, (c) визуализация нагретого кантилевера в аустените выше температуры магнитоструктурного фазового перехода.

расположенными длинными ребрами $c_{M}$ моноклинной кристаллической решетки. Данная изгибная деформация состоит из деформации за счет двойникования, когда при внешней нагрузке растут благоприятно ориентированные моноклинные кристаллы мартенсита, и упругой деформации мартенсита. Игла наноманипулятора отводилась от микрокантилевера, после чего микрокантилевер проявлял упругие свойства и возвращался частично к своей первоначальной форме, наблюдалось остаточная деформация только за счет двойникования (рис. 3,b). Для нагрева микрокантилевера $\mathrm{Ni}_{50} \mathrm{Mn}_{18.5} \mathrm{Ga}_{25} \mathrm{Cu}_{6.5}$ он помещался в область светового пятна лазера (лазер был выключен). Лазер выполнен на основе гетероструктуры $\mathrm{GaAl} / \mathrm{GaAlAs}$ с длиной волны $0.9 \mu \mathrm{m}$. ИК-лазер включали и микрокантилевер $\mathrm{Ni}_{50} \mathrm{Mn}_{18.5} \mathrm{Ga}_{25} \mathrm{Cu}_{6.5}$ нагревался до температуры выше обратного магнитоструктурного фазового перехода, в результате чего он переходил в аустенитную фазу и принимал свою первоначальную форму (рис. 3,c). Нагрев микрокантилевера $\mathrm{Ni}_{50} \mathrm{Mn}_{18.5} \mathrm{Ga}_{25} \mathrm{Cu}_{6.5}$ выше температуры магнитоструткрурного перехода перевел весь объем образца в кубическую аустенитную фазу. Внешняя сторона изогнутого микрокантилевера уменьшилась за счет уменьшения параметра $c_{M}$ кристаллической решетки из моноклинной в кубическую фазу. В результате микрокантилевер $\mathrm{Ni}_{50} \mathrm{Mn}_{18.5} \mathrm{Ga}_{25} \mathrm{Cu}_{6.5}$ выпрямится. Наблюдался эффект памяти формы.
Была проведена серия экспериментов для визуального наблюдения проявления эффекта памяти формы в микрокантилевере ферромагнитного сплава Гейслеpa $\mathrm{Ni}_{50} \mathrm{Mn}_{18.5} \mathrm{Ga}_{25} \mathrm{Cu}_{6.5}$ (таблица). Были осуществлены следующие изгибные деформации $1.1,3.9,7.5 \%$. После снятия изгибающей нагрузки (игла наноманипулятора отведена от микрокантилевера) в первую очередь наблюдалась упругая деформация в мартенситной моноклинной фазе $\varepsilon_{z}$, которая составила $0.85,2.7,4.1 \%$ соответственно, и остаточная деформация микрокантилевера за счет двойникования $\varepsilon_{T W} 0.25,1.2$ и $3.4 \%$ соответственно. Упругая деформация микрокантилевера в мартенситной моноклинной фазе рассчитывалась по формуле $\varepsilon_{z}=(y / r-y / R) \cdot 100 \%$, а остаточная деформация за счет двойникования $\varepsilon_{T W}=y / R \cdot 100 \%$, где $y$ - толщина участка приращения, $r$ - радиус кривизны при изгибной деформации, $R$ - радиус кривизны микрокантилевера при остаточной деформации. При всех значениях остаточной деформации микрокантилевер возвращался к своей первоначальной форме. Видно, что упругая деформация микрокантилевера $\mathrm{Ni}_{50} \mathrm{Mn}_{18.5} \mathrm{Ga}_{25} \mathrm{Cu}_{6.5}$ по величине превышает значение эффекта памяти формы. В самом начале изгиба (большой радиус кривизны) упругая деформация микрокантилевера может быть в три раза больше эффекта памяти формы, а при малых радиусах изгиба они могут быть равны по величине.

Значения деформации микрокантилевера

\begin{tabular}{c|c|c|c|c|c}
\hline $\begin{array}{c}\text { № } \\
\text { п/п }\end{array}$ & $\begin{array}{c}\text { Радиус кривизны } \\
\text { при изгибной } \\
\text { деформации } r, \mu \mathrm{m}\end{array}$ & $\begin{array}{c}\text { Радиус кривизны } \\
\text { при двойниковании } \\
R, \mu \mathrm{m}\end{array}$ & $\begin{array}{c}\text { Толщина участка } \\
\text { приращения } \\
y, \mu \mathrm{m}\end{array}$ & $\begin{array}{c}\text { Деформация при } \\
\text { двойниковании } \\
\varepsilon_{T W}=y / R \cdot 100 \%, \%\end{array}$ & $\begin{array}{c}\text { Упругая деформация } \\
\text { мартенсита } \\
\varepsilon_{z}=(y / r-y / R) \cdot 100 \%, \%\end{array}$ \\
\hline 1 & 58 & 256 & 0.64 & 0.25 & 0.85 \\
2 & 17 & 53 & 0.64 & 1.2 & 2.7 \\
3 & 8.5 & 19 & 0.64 & 3.4 & 4.1
\end{tabular}


Перспектива применения сплавов с магнитоуправляемыми деформациями прежде всего связана с использованием их в качестве исполнительных элементов микроэлектромеханических систем (МЭМС). Такое применение подразумевает отличные условия окружающей среды от приведенного здесь эксперимента, который проводился в глубоком вакууме. Использование МЭМС в воздушной среде делает актуальным вопрос связи адсорбции и сил поверхностного натяжения. Известно, что в микрообразцах силы поверхностного натяжения могут смещать температуры магнитоструткурного фазового перехода [11]. Так же адсорбция в воздушной среде меняет силы поверхностного натяжения [12] и, таким образом, косвенно может сдвигать характерные температуры магнитоструктурного фазового перехода. Помимо адсорбции на поверхностный слой микрокантилевера влияет его технология изготовления. Фокусированный ионный пучок может приводить к аморфизации поверхностного слоя микрокантилевера $[9,13]$. Менее упругий аморфный слой на поверхности микрокантилевера сместит характерные температуры магнитоструктурного фазового перехода в область более низких температур. Вышеназванные эффекты приводят к изменению функциональных свойств микрокантилевера $\mathrm{Ni}_{50} \mathrm{Mn}_{18.5} \mathrm{Ga}_{25} \mathrm{Cu}_{6.5}$, и их необходимо учитывать при разработке и конструировании МЭМС.

\section{5. Заключение}

В настоящей работе был продемонстрирован эффект памяти формы в микроразмерном образце ферромагнитного сплава Гейслера $\mathrm{Ni}_{50} \mathrm{Mn}_{18.5} \mathrm{Ga}_{25} \mathrm{Cu}_{6.5}$ габаритными размерами $23 \times 1.28 \times 4, \mu \mathrm{m}$. В микрокантилевере при продольно-поперечном изгибе в мартенситной фазе была обнаружена упругая деформация, которая по порядку величины равна значениям эффекта памяти формы. Проявления двусторонней памяти формы обнаружить не удалось. Применение магнитных сплавов с эффектом памяти формы в качестве исполнительных элементов микросистемной техники в микро- и наноэлектроники, биотехнологиях и медицине на данный момент возможно в составе биморфных композитов, используя лишь односторонний эффект памяти формы.

\section{Благодарности}

Авторы выражают благодарность D. Zhao, J. Liu (Институт материаловедения и инженерии города Нимбо Китайской академии наук) за синтез исходного образца.

\section{Финансирование работы}

Экспериментальная часть наблюдения эффекта памяти формы была выполнена за счет средств субсидии, выделенной на реализацию Программы повышения конкурентоспособности 5-100 Балтийского федерального университета им. И. Канта, остальная часть работы выполнена при финансовой поддержке РФФИ и Правительства Москвы в рамках научного проекта № 19-37-70012.

\section{Конфликт интересов}

Авторы заявляют, что у них нет конфликта интересов.

\section{Список литературы}

[1] В.Д. Бучельников, А.Н. Васильев, В.В. Коледов, С.В. Таскаев, В.В. Ховайло, В.Г. Шавров. УФН 176, 900 (2006).

[2] A.P. Kamantsev, V.V. Koledov, A.V. Mashirov, E.T. Dilmieva, V.G. Shavrov, J. Cwik, A.S. Los, V.I. Nizhankovskii, K. Rogacki, I.S. Tereshina, Y.S. Koshkid'ko. J. Appl. Phys. 117 (16), 163903 (2015).

[3] А.Н. Васильев, В.Д. Бучельников, Т. Такаги, В.В. Ховайло, Э.И. Эстрин. УФН 173, 577 (2003).

[4] D.S. Kuchin, E T. Dilmieva, Y.S. Koshkid'ko, A.P. Kamantsev, V.V. Koledov, A.V. Mashirov, V.G. Shavrov, J. Cwik, K. Rogacki, V.V. Khovaylo. J. Magn. Magn. Mat. 482, 317 (2019).

[5] P. Devi, M.G. Zavareh, C.S. Mejía, K. Hofmann, B. Albert, C. Felser, M. Nicklas, S. Singh. Phys. Rev. Materials 2, 122401 (2018).

[6] E. Kalimullina, A. Kamantsev, V. Koledov, V. Shavrov, V. Nizhankovskii, A. Irzhak, F. Albertini, S. Fabbrici, P. Ranzieri, P. Ari-Gur. Phys. Status Solidi C 11, 5-6, 1023 (2014).

[7] M. Kohl, B. Krevet, M. Ohtsuka, D. Bruggerhl, Y. Liu. Mater. Transact. 47, 3, 639 (2006).

[8] M. Kohl, M. Schmitt, A. Backen, L. Schultz, B. Krevet, S. Fahler. Appl. Phys. Lett. 104, 043111 (2014).

[9] D. Zakharov, G. Lebedev, A. Irzhak, V. Afonina, A. Mashirov, V. Kalashnikov, V. Koledov, A. Shelyakov, D. Podgorny, N. Tabachkova, V. Shavrov. Smart Mater. Struct. 21, 052001 (2012).

[10] D. Zhao, T. Castán, A. Planes, Z. Li, W. Sun, J. Liu. Phys. Rev. B 96, 224105 (2017).

[11] A.V. Mashirov, A.V. Irzhak, N.Yu. Tabachkova, F.O. Milovich, A.P. Kamantev, D. Zhao, J. Liu, V.G. Kolesnikova, V.V. Rodionova, V.V. Koledov. IEEE Magn. Lett. 10, 1 (2019).

[12] А.Я. Гохштейн. Поверхностное натяжение твердых тел и адсорбция. Наука, М. (1976). 400 c.

[13] A. Irzhak, V. Koledov, D. Zakharov, G. Lebedev, A. Mashirov, V. Afonina, K. Akatyeva, V. Kalashnikov, N. Sitnikov, N. Tabachkova, A. Shelyakov. J. Alloys Compd. 586, S464 (2014).

Редактор К.В. Емцев 